\title{
Sağlık Hizmetleri Meslek Yüksekokulu Öğrencilerinin Kan Bağışına Karşı Tutum ve Davranışları
}

\author{
Attitudes and Behaviors of Vocational School of Health Services Students Towards Blood \\ Donation
}

Halil SOYAL, Onur YARAR

ÖZ

Hayati önem taşıyan ve insan vücudu dışında üretilemeyen kan ve kan ürünleri tedavide tedavi yaşamsal bir öneme sahiptir. Yaşam süresindeki artışa bağlı pek çok ülkede kan ve kan ürünlerine olan gereksinim artmış, kanın temin edilmesi önem kazanmıştır. Dünya sağlık örgütü, ihtiyaç duyulan kanın; gönüllü karşılık beklemeksizin düzenli ve bilinçli kan bağışçılarından temin edilmesini en güvenilir kan temin yolu olarak benimsemiştir. Ülkemizde güvenli kanın temin edilmemesindeki en önemli problem, gönüllü kan bağışındaki yetersizlik, halkın yanlış inanışları ve tutumlara sahip olmasıdır. Bu araştırma Okan Üniversitesinde Sağlık Hizmetleri Meslek Yüksek Okulu öğrencilerinin kan bağışına karşı tutum ve davranışlarının incelenmesi, öğrencileri kan bağışından uzak tutan nedenlerin araştırılması, bu veriler 1şığında gönüllü kan bağış1 bilinci oluşturulmasında çözüm önerilerinin belirlenmesi amacıyla planlanmıştır.

Anahtar Kelimeler: Kan, Kan bağışı, Sağlık Hizmetleri Meslek Yüksek Okulu

\begin{abstract}
Treatment with blood and blood products that are vital and can not be produced outside the human body has a vital prescription. In many countries linked to the increase in life expectancy, the need for blood and blood products has increased, and the provision of blood has become more important. The world health organization needs the blood; As the most reliable means of providing blood, to be provided from regular and conscious blood donors without waiting for voluntary service. The most important problem in ensuring safe blood in our country is the inability to donate blood, the wrong beliefs and attitudes of the people. This research was planned to examine the attitudes and behaviors of the Vocational School of Health Services students to blood donation at Okan University, to investigate the reasons that students are away from donation and to determine the solution proposal for volunteer blood donation awareness formation in this data.
\end{abstract}

Keywords: Blood, Blood Donation, Vocational School of Health Services

\section{GÍRİŞ}

Kan, geçmişten günümüze sağlığın ve yaşamın temel simgesi olarak "kaynağı insan olan ve elde edilmesi için başka alternatifi olmayan eşsiz bir tedavi aracı" olarak bilinmektedir (1). Kan transfüzyonlarının ana amacı, kaybedilen kanın yerine konmasıdır. Günümüzde bile, kan ve kandan elde edilen ürünler laboratuvar koşullarında elde edilemez ve dolayısıyla da yaşamsal özelliği olan bu sıvı, toplumdaki sağlıklı bireylerden sağlanmak zorundadır (2). Kan transfüzyonunun doğru endikasyonlar da yapıldığında hayat kurtarıcı olduğu kesindir ve kanın sağlandığı tek kaynak da donörlerdir. Bu nedenlerle de kan merkezleri, hizmet verdikleri hastalara gerekli kanı sağlayabilmek için sorumluluk sahibi donörlere (bağışçılara) ihtiyaç duyarlar, zira kan temininde temel prensip, gönüllü ve karşılıksız bağıştır (3).
Halil SOYAL ( $\square)$

Okan Üniversitesi Sağllk Hizmetleri Meslek Yüksekokulu

Tepeören Mahallesi, Okan Üniversitesi Tuzla Kampüsü, 34959 Akfirat/ Tuzla/Istanbul

e-posta:halil.soyal@okan.edu.tr 
Günümüzde kan verilmesi gereken hastalarda kanın yerini tutabilecek bir madde yapılamamıştır. Bu konuda çalışmalar olmakla beraber, henüz kanın yerine kullanılan başka bir madde yoktur. Kan, doğru kullanıldığı takdirde yaşam kurtaran bir biyolojik ilaçtır (4).

Ulusal kan politikasının amaçları; gönüllü, karşılıksız, düzenli bağışçılardan iyi donanımlı merkezlerde toplanan, kolayca ulaşılabilir, güvenli, kaliteli ve yeterli miktarda transfüzyonla geçen ve enfeksiyon taşımayan, uygun şekilde hazırlanan, taşınan kan ve kan ürünü sağlamaktır $(2,5)$.

Kan bağışının öneminin daha da fazla hissedildiği şu dönemlerde ülkemizde kan bağışı için gerek kamu gerekse de özel kuruluşlar tarafından bağış kampanyaları düzenlenmektedir. $\mathrm{Bu}$ kampanyalarda temel amaç, kan bağışının yararlarını ve kan bağışının ülkemiz için önemini anlatmaktır. $\mathrm{Bu}$ bağışlarda, özendirici çeşitli çalışmalar yapılarak da kan bağışındaki oran arttırılmaya çalışılmaktadır. Kan bağışı konusunda, üniversite öğrencilerinin önemi daha genç ve sağlıklı nüfusun fazla olması nedeniyle daha da artmaktadır.

Kan bağışının insan sağlığı için bu kadar önemli olmasına rağmen ülkemizde bağış hakkında bilgi oranı oldukça düşüktür ve bu durum kan bağışı oranını düşürmektedir. Gönüllü kan bağışı ile karşılanamayan kısım, hastane kan merkezleri tarafından çoğunlukla replasman, kana kan, zorunlu yöntem ile karşılanmıştır ve karşılanmaktadır. Gelişmiş ülkelerde gönüllü kan bağışlarının nüfusa oranı $\% 5$ 'e ulaşırken bu oran ülkemizde \%3,6 civarındadır. Gönüllü kan bağışçılarının sayısındaki yetersizlik karşımıza önemli bir problem olarak çıkmaktadır (6).

$\mathrm{Bu}$ nedenle bu çalışma yeni neslin sağlıkçı adayları olan Sağlık Hizmetleri Meslek Yüksek Okulu öğrencilerinin kan bağışı hakkında bilgi ve düşüncelerini ortaya koyup kan bağışından uzak tutan nedenlerin belirlemesi amacıyla planlanmıştır.

\section{GEREÇ ve YÖNTEM}

Bu çalışma, 2015-2016 eğitim yılı bahar döneminde Okan Üniversitesi Sağlık Hizmetleri Meslek Yüksek Okulu programlarında eğitim gören öğrencilerde gerçekleştirilmiş kesitsel bir çalışmadır. Öğrencilerin demografik özelliklerinin de bulunduğu 20 sorudan oluşan bir soru formu uygulanmıştır. Soru formunda kan bağışı ile ilgili olarak öğrencilerin genel yaklaşımlarını ve tutumlarını ve kan bağışı ile ilgili olabilecek çeşitli demografik özelliklerini belirlemeye yönelik sorular yer almaktadır. Veriler bilgisayar ortamına aktarılarak SPSS 11.5 yazılımı aracılığıyla analiz edilmiştir. Verilerin değerlendirilmesinde minimum, maksimum, ortalama, yüzde değerleri ve ki kare testi kullanılmıştır.

\section{BULGULAR}

Sağlık Hizmetleri Meslek Yüksek Okulu öğrencilerinin katılmış olduğu bu çalışmada \%45,66'sı (773) kan bağışı yapmış olduğunu ifade etmiştir. Katılımcıların \%56,11'ini kadınlar oluştururken kan bağışı yapmışların içerisinde en fazla sağlık meslek lisesi mezunu yer almaktadır.

Öğrencilerin yaş ortalamas1, 20,54 $\pm 1,12$ olup, Tablo 1 'de öğrencilerin diğer bireysel özelliklerinin dağılımı görülmektedir. Ayrıca kan bağışı yapma durumu yaş ve öğrencilerin aile gelir durumlarına göre istatistiksel olarak incelendiğinde anlamlı bulunmuştur.

Tablo 1. Öğrencilerin Demografik özelliklerinin kan bağışına etkisi

\begin{tabular}{llll}
\hline & & $\begin{array}{l}\text { Kan Bağışı } \\
\text { Yapmış } \\
\text { Sayı }(\%)\end{array}$ & $\begin{array}{l}\text { Kan Bağışı } \\
\text { Yapmamış } \\
\text { Sayı }(\%)\end{array}$ \\
\hline \multirow{2}{*}{ Cinsiyet } & Erkek & $398(23,51)$ & $345(20,38)$ \\
& Kadın & $375(22,15)$ & $575(33,96)$ \\
& $18-19$ & $151(8,91)$ & $265(15,65)$ \\
Yaş & $20-21$ & $133(7,85)$ & $332(19,61)$ \\
& $22-23$ & $158(9,33)$ & $189(11,16)$ \\
& $24-25$ & $166(9,80)$ & $86(5,08)$ \\
Lise & $26-27$ & $136(8,03)$ & $32(1,89)$ \\
& $28>$ & $29(1,71)$ & $16(0,95)$ \\
& Anadolu Lisesi & $231(13,64)$ & $195(11,52)$ \\
& Sağlık Meslek Lisesi & $288(17,01)$ & $323(19,08)$ \\
& Düz Lise & $207(12,23)$ & $364(21,50)$ \\
Ailesinin Gelir & Dar Gelirli & $47(2,77)$ & $38(2,24)$ \\
& Diğer & $162(9,56)$ & $197(11,64)$ \\
& Düsüü Gelirli & $244(14,41)$ & $181(10,69)$ \\
& Yüta Gelirli & $312(18,43)$ & $479(28,29)$ \\
& & $55(3,24)$ & $63(3,721)$ \\
\hline
\end{tabular}

Tablo 2'ye göre kan bağışında bulunan bireylerin \%29,08'i kan bağışçısı olmadan önce kan vermeye ilişkin endişelerinin başında ihtiyaç sahiplerine para ile satıldığı düşüncesinin olduğu cevabını vermiştir. Kan bağışı yapmamış bireyler ile kan bağışı yapmamasındaki etkenler arasında anlamlı bir ilişki bulunmuştur. Kan merkezine başvurup kan bağışı yapmamış bireylerin \%31,41'inin kan bağışı yapmamasındaki neden, kanının kendine yetecek kadar olduğu yani kan bağışında bulunursa kansız kalacağı korkusudur. 
Tablo 2. Kan bağışı yapmış bireyler ile endişeleri arasındaki ilişki ve kan bağışı yapmamış bireyler ile yapmama etkenleri arasındaki ilişki

\begin{tabular}{|c|c|c|c|}
\hline & & $\begin{array}{l}\text { Kan Bağış1 } \\
\text { Yapmış } \\
\mathrm{n}(\%)\end{array}$ & \\
\hline \multirow{7}{*}{$\begin{array}{l}\text { Kan verme } \\
\text { ile ilgili } \\
\text { endişeleri }\end{array}$} & İştahım artar & $116(17,39)$ & \multirow{6}{*}{$\mathrm{p}=0,144$} \\
\hline & Halsiz kalırım & $111(16,64)$ & \\
\hline & Kansız kalırım & $46(6,89)$ & \\
\hline & Para ile satılır & $194(29,08)$ & \\
\hline & Hastalık bulaşır & $114(17,09)$ & \\
\hline & Bağımlılık yapar & $86(12,89)$ & \\
\hline & & $\begin{array}{l}\text { Kan Bağışı } \\
\text { Yapmamış } \\
\mathrm{n}(\%)\end{array}$ & \\
\hline \multirow{5}{*}{$\begin{array}{l}\text { Kan bağışı } \\
\text { yapmama } \\
\text { etkenleri }\end{array}$} & Benim kan grubumdan çok var & $145(18,14)$ & \multirow{5}{*}{$\mathrm{p}=0,012$} \\
\hline & İlaç aldım kan veremem & $102(12,76)$ & \\
\hline & Kanım bana yetecek kadar & $251(31,41)$ & \\
\hline & Hastalık bulaşabilir endişesi & $177(22,15)$ & \\
\hline & Kan tutma/iğne korkusu & $124(15,51)$ & \\
\hline
\end{tabular}

Tablo 3'e göre ülkemizde kan bağışının ihtiyacı karşılama durumu ile kan bağışları birbirine göre bağımlı bulunmuştur. Kan bağışı yapmamış olan bireylerin \%57,7'si de ülkemizde kan bağışının yeterli durumda olmadığını belirtmiştir.

Tablo 3. Kan bağışı durumunun öğrencilerin kan bağış1 görüşlerine etkisi

\begin{tabular}{|c|c|c|c|}
\hline & & $\begin{array}{l}\text { Kan Bağış1 } \\
\text { Yapmış } \\
\mathrm{n}(\%) \\
\end{array}$ & $\begin{array}{l}\text { Kan Bağış1 } \\
\text { Yapmamış } \\
\mathrm{n}(\%)\end{array}$ \\
\hline \multirow{2}{*}{$\begin{array}{l}\text { Ülkemizde } \\
\text { Kan Bağışı } \\
\text { Yeterlilik } \\
\text { durumu }\end{array}$} & Evet & $412(24,33)$ & $\begin{array}{l}389 \\
(22,97)\end{array}$ \\
\hline & Hayır & $361(21,32)$ & $\begin{array}{l}531 \\
(31,36) \\
\end{array}$ \\
\hline \multirow{4}{*}{$\begin{array}{l}\text { Düzenli } \\
\text { olarak kan } \\
\text { bağışlamaya } \\
\text { yöneltecek } \\
\text { en önemli } \\
\text { etkenler }\end{array}$} & Sağlığa yararlı olması & $114(6,73)$ & $188(11,1)$ \\
\hline & $\begin{array}{l}\text { Kana ihtiyacım olabileceğini } \\
\text { düşünmek }\end{array}$ & $245(14,47)$ & $354(20,9)$ \\
\hline & Bir hayat kurtarma düşüncesi & $320(18,90)$ & $\begin{array}{l}297 \\
(17,54)\end{array}$ \\
\hline & Anonslar & $94(5,55)$ & $81(4,78)$ \\
\hline \multirow{6}{*}{$\begin{array}{l}\text { Ülkemizde } \\
\text { kan bağışı } \\
\text { nasıl } \\
\text { attırılabilir? }\end{array}$} & Okullarda Eğitim & $201(11,87)$ & $\begin{array}{l}264 \\
(15,59)\end{array}$ \\
\hline & Basın-Yayın & $122(7,20)$ & $111(6,55)$ \\
\hline & $\begin{array}{l}\text { Şehir Merkezlerine araç } \\
\text { yerleştirme }\end{array}$ & $75(4,43)$ & $97(5,72)$ \\
\hline & $\begin{array}{l}\text { Kişi yada yakınlarına kan } \\
\text { bulma garantisi }\end{array}$ & $161(9,50)$ & $145(8,56)$ \\
\hline & Kolay ulaşım imkanı & $88(5,19)$ & $138(8,15)$ \\
\hline & Ödül/hediye verme & $126(7,44)$ & $165(9,74)$ \\
\hline
\end{tabular}

Düzenli olarak kan bağışlamaya yöneltmede en önemli etkenlerin ne olduğu sorulduğunda kan vermişöğrencilerinde kan bağışı yapmamış öğrencilerinde çoğunluğu yani çalışmaya katılanların \%36,44'ü bir hayat kurtarma düşüncesi olduğunu belirtirken, \%35.37'si kan ihtiyac1 olabileceğini düşünmektedir. Ülkemizde kan bağışını nasıl arttırabileceğimiz sorulduğunda ise öğrencilerin \%27,46's1 okullarda bunun eğitim olarak verilmesi gerektiğini belirtmiştir ve bu kan bağışı durumuna göre istatistiksel olarak incelendiğinde anlamlı olduğu gözlenmiştir.

\section{TARTIŞMA}

Araştırmaya katılanların tanıtıcı özelliklerine bakıldığında; katılımcıların 743'ü $(\% 43,9)$ erkek, 950'si $(\% 56,1)$ kadınlardan olmak üzere toplam 1693 kişiden oluştuğu görülmektedir. Kan bağışını yapanların oranı ile cinsiyetler arasındaki ilişkiye bakıldığında, kan bağışı yapan katılımc1ların, $\% 51,5$ ' inin erkeklerden, \%48,5' inin kadınlardan oluştuğu görülmüsstür. Kızılay kan hizmetlerinin 2011 yılı cinsiyet dağılımı verilerine göre, kan bağışında bulunan bireylerin \% 94'ünü erkek, \% 6'sını kadın bireyler oluşturmaktadır (7). 2012 yılında ise kan bağışı yapma oranı erkeklerde $\% 91$ iken, kadınlarda ise \% 9 olarak belirlenmiştir(8). 2014 yılında ise kan bağı̧̧ı yapanların \%57,9'u erkek iken \%42,2'si kadınlardan oluşmaktadır (9). Yaptığımız çalışmanın sonuçları ile önceki yıllara ait veriler karşılaştırıldığında, erkeklerin kadınlara oranla daha fazla kan bağışında bulundukları söylenebilmektedir.

Araştırmamızda kan bağışında bulunanların kan bağışında bulunmadan önceki endişeleri sorulduğunda $\% 29,1$ 'inde kanın ihtiyaç sahiplerine para ile satıldığı düşüncesinin olduğu, \% 17,4' ünün iştah artmasına ve buna bağlı olarak kilo almasına neden olabileceği, \%17,1'inin hastalık bulaşma korkusunun olduğu görülmektedir. Ülkemizde yapılan araştırma sonuçları da benzer özellikler göstermektedir. Kaya ve arkadaşlarının yaptığ 1 çalışmada, öğrencilerin $\% 74,8$ 'i bağışlanan kanın para karşıllığ satılmasından kuşkulanmaktadır. Yaşar ve arkadaşlarının yaptığı araştırmada katılımcıların \% 13'nün kan bağışı ile hastalık bulaşır endişesiyle kan vermedikleri söylenmiştir (10).

\section{SONUÇ}

Çalışma, Sağlık Hizmetleri Meslek Yüksekokulu bünyesindeki 18 program öğrencisi üzerinde gerçekleştirilmiştir. Çalışamaya katılan öğrencilerin 
\%45,66's1 kan bağışında bulunduğunu belirtmiştir. Çalışmada elde edilen sonuçlara göre incelenen grubun toplumda kan bağışı yoluyla hastalık bulaşması, kansız kalmak, kanın ihtiyaç sahiplerine parayla satılması gibi inanışların giderilmesinde toplumun bilgilendirilmesi ve motivasyonunu sağlayacak faaliyetlerin yaygın olarak yapılması gerekir. Ayrıca kan bağış alanlarının toplumun ulaşabilecekleri yerlerde ve temiz olması, kan bağışının artmasında önemli etkendir. Kan bağışçılarının düzenli kan bağışçısı olması için ilk deneyimin önemli etkisi vardır. Bu nedenle kan merkezlerinde çalışan personelin tutum ve davranışları kan bağışçısı olmada önemli bir faktördür.

Toplumda kan bağışı hakkında bilinç oluşturulması ve kan bağışını teşvik etmek için gençlerin yoğun olarak bulunduğu okullar, kurumlar seçilerek kan bağışı hakkında eğitimlerin yapılması, kitle-iletişim araçlarıyla gençleri hedefleyen mesajlar verilerek gönüllü kan bağışı özendirilebilir.

\section{KAYNAKLAR}

1. Hablemitoğlu ve ark;Bir Fedakâkarlık Örneği Olarak "Kan Bağışı" ; Aile ve Toplum Yı1: 11 Cilt: 5 Sayı: 20 Ocak-ŞubatMart 2010 ISSN: 1303-0256
2. Kaya ve ark; Süleyman Demirel Üniversitesi Tıp Fakültesi Kan Merkezi'nin 2000-2007 yılları tarama test sonuçları;S.D.Ü. Tıp Fak. Derg. 2009:16(2)/13-15

3. Bilgen İ.Ü. Cerrahpaşa Tıp Fakültesi Sürekli Tıp Eğitimi Etkinlikleri Herkes İçin Transfüzyon Tıbbı Sempozyum Dizisi No: $44 \cdot$ Mayıs 2005; s. 15-42

4. Keskinler DÜ.Erzurum Kızılay Kan Merkezi'ne başvuran kan donörlerinin $\mathrm{HBV}$ ve $\mathrm{HCV}$ yönünden serolojik değerlendirilmesi. İnönü Üniversitesi T1p Fakültesi Dergisi2003;10:195-8

5. M. Bayık, 'Kan bankacıllğg ve transfüzyon tıbbı tarihi',Herkes İçin Transfüzyon Tibbi Sempozyum Dizisi, 44 (2005a), pp. 9-14

6. http://www.kanver.org/sayfa/e-kutuphane/dunyada-veturkiye-de-kan-bankaciligi/43, Erişim Tarihi: 23.08.2016

7. Türk Kızılayı, “'Kan Hizmetleri Genel Müdürlüğü Faaliyet Kitabı", Ankara, 2011,1 - 105.

8. Türk Kızılay1, “ Kan Hizmetleri Genel Müdürlügü Faaliyet Kitabı", Ankara, 2012,1-110

9. Şıhbaraklığlu H. Kayseri ilinde toplumun kan bağışına karşı tutum ve davranışları, Yüksek Lisans Tezi, Okan Üniversitesi Sağlık Bilimleri Enstitüsü, İstanbul, Türkiye, 2014.

10. Yaşar K, Pehlivanoğlu F, Iş̧k M. Emirhan, Çiçek G, “ Ne Kadar Farkındayız Doktor Anketi”, Haseki Tip Bülteni, 2011, 49: 56-61. 